\title{
MÉTODOS DE ENXERTIA E AMBIENTES NA PRODUÇÃO DE MUDAS DE PESSEGUEIRO CV. 'DIAMANTE'’
}

\author{
Janaine Myrna Rodrigues Reis ${ }^{2}$, Nilton Nagib Jorge Chalfun ${ }^{3}$, Marcelo de Almeida Reis ${ }^{4}$
}

\begin{abstract}
GRAFTING METHODS AND ENVIRONMENTAL

CONDITIONS FOR PRODUCING PEACH-TREE CV. 'DIAMANTE' SEEDLINGS

Seedling quality is essential for producing quality fruits and keeping the producer revenue. The main goal of this research was to investigate the effect of different environmental conditions and three grafting methods in the production of peach-tree seedlings (Prunus persica (L.) Batsch). The experiment took place at the Universidade Federal de Lavras, Minas Gerais State, Brazil. The experimental design was completely randomized, in a $3 \times 3$ factorial scheme (three environments: plastic greenhouse, mesh of $50 \%$ of shading, and open field; and three grafting methods: shield budding, patch budding, and cleft grafting), with four replications and 12 plants per plot. 'Okinawa' was the rootstocks used, and buddings and grafts originated from the 'Diamante' peach-tree cultivar. The features evaluated were grafttake (\%) and time to reach the first formation pruning (days). It was concluded that the mean average graft-take percentage for all three grafting methods was $91.94 \%$, independently of the environment. For all three environmental conditions studied, seedlings grafted according to the cleft grafting method were the fastest ones to reach the first formation pruning, while the patch budding method allowed less time for the first formation pruning, for the open field and mesh environments, when compared with the shield budding method.
\end{abstract}

KEY-WORDS: Prunus persica (L.); environmental conditions; propagation.

\section{INTRODUÇÃO}

A fruticultura moderna está orientada, cada vez mais, para a busca de tecnologias que possibilitem a produção de frutas de alta qualidade, com os menores investimentos possíveis (Medeiros et al. 2002).

O objetivo de todo viveirista é produzir mudas de plantas frutíferas com elevado padrão de qualidade.

\section{RESUMO}

A qualidade da muda é fator essencial para o estabelecimento de um pomar produtivo, capaz de produzir frutos de qualidade, mantendo a renda do produtor. O objetivo deste trabalho foi estudar o efeito de diferentes ambientes e três métodos de enxertia, na produção de mudas de pessegueiro (Prunus persica (L.) Batsch). O trabalho foi conduzido no Setor de Fruticultura da Universidade Federal de Lavras (MG). O delineamento experimental adotado foi inteiramente ao acaso, em esquema fatorial $3 \times 3$ (três ambientes: estufa plástica, telado e campo aberto; e três tipos de enxertia: borbulhia em T normal, borbulhia em placa e garfagem de fenda cheia), com quatro repetições e 12 plantas por parcela. O porta-enxerto utilizado foi o pessegueiro 'Okinawa' e as borbulhias e garfos foram retirados da cultivar de pessegueiro 'Diamante'. As características avaliadas foram pegamento da enxertia (\%) e tempo para a muda atingir a primeira poda de formação (dias). Concluiu-se que a porcentagem média de pegamento dos três tipos de enxertias foi de 91,94\%, independentemente do ambiente. Verificou-se que, nos três ambientes estudados, as mudas enxertadas por garfagem atingiram mais rápido a primeira poda de formação e que a enxertia de borbulhia em placa propiciou menor tempo para a primeira poda de formação em campo aberto e telado, quando comparada com a enxertia de borbulhia em $\mathrm{T}$.

PALAVRAS-CHAVE: Prunus persica (L.); condições ambientais; propagação.

Esta meta é essencial para garantir a competitividade do viveiro e o retorno do investimento efetuado no estabelecimento da atividade, além de assegurar ao cliente a satisfação de suas necessidades e ao produtor de mudas a idoneidade e estabilidade do empreendimento, durante anos (Fachinello et al. 2005). A qualidade da muda e o tempo para sua formação são a base do pomar e do sucesso da exploração frutícola.

1. Trabalho recebido em dez./2008 e aceito para publicação em abr./2010 (n ${ }^{\circ}$ registro: PAT 5302/ DOI: 10.5216/pat.v40i2.5302).

2. Centro Universitário de Patos de Minas (Unipam), Faculdade de Engenharia e Ciências Agrárias, Patos de Minas, MG, Brasil.E-mail: janaine.reis@bol.com.br.

3. Universidade Federal de Lavras (UFLa), Departamento de Agricultura, Lavras, MG, Brasil.E-mail: nchalfun@ufla.br. 4. Universidade Federal de Uberlândia (UFU), Fapemig/Instituto de Ciências Agrárias, Uberlândia, MG, Brasil. 
No Brasil, a área plantada com pessegueiro (Prunus persica (L.) Batsch) é de, aproximadamente, 21.000 ha (Picolotto et al. 2007), sendo, portanto, uma importante cultura para o País. Atualmente, o pessegueiro é propagado por meio de enxertia da cultivar copa sobre porta-enxerto proveniente de sementes (Tofanelli et al. 2001), apresentando vantagens como facilidade de obtenção da muda, vigor do porta-enxerto, longevidade da planta e, principalmente, rendimento em viveiro (Hoffmann et al. 2003).

A variedade 'Okinawa' é um dos portaenxertos mais utilizados na produção de mudas, na região do sul de Minas, sendo utilizada em 70\% das plantas enxertadas. Segundo Simão (1998), esta variedade é vigorosa e resistente a nematóides e é a mais indicada, tanto para pessegueiro como para a nectarina e a ameixeira.

O método de enxertia mais utilizado é a borbulhia de gema ativa, realizada, em geral, entre fins de novembro e meados de dezembro, permitindo a produção da muda em, aproximadamente, oito meses após a enxertia. Também pode ser realizada a enxertia de gema dormente, no outono, porém o tempo de produção torna-se mais longo (aproximadamente 15 meses). Ainda pode ser realizada a garfagem, durante o inverno, obtendo-se a muda em 12 meses (Medeiros et al. 2002). No entanto, a garfagem apresenta o inconveniente de estar associada à ocorrência de gomose na muda, o que pode comprometer a sua sobrevivência (Hoffmann et al. 2003). Tanto a enxertia de gema dormente como a garfagem são realizadas visando ao aproveitamento de porta-enxertos, cuja enxertia de borbulhia de gema ativa não obteve êxito, ou que não apresentavam diâmetro suficientemente adequado para o processo de enxertia (Chalfun \& Hoffmann 1997, Medeiros et al. 2002, Hoffmann et al. 2003, Fachinello et al. 2005).

A enxertia de placa pode ser realizada em diversas épocas do ano, pois não exige que o porta-enxerto solte a casca. Entretanto, quase não é utilizada na produção comercial de mudas de pessegueiro, que, tradicionalmente, é realizada por meio da borbulhia em T.

A utilização de temperaturas mais elevadas e constantes, obtidas em ambientes controlados, como casas-de-vegetação, tem proporcionado maior precocidade na produção de diversas culturas.

O cultivo em casa-de-vegetação possibilita vantagens como aumento da qualidade do produto, precocidade obtida pelas melhores condições ambientais internas, menor lixiviação de nutrientes do solo, melhor controle de pragas e doenças e melhor manejo de água, além de proteção contra adversidades climáticas (Oliveira 1997).

Nunes (2001) testou dois diferentes ambientes para crescimento de porta-enxertos de macieira: sala de crescimento com temperatura de $24 \pm 1^{\circ} \mathrm{C}$, fotoperíodo de 16 horas, intensidade luminosa (RFA) de $50 \mu \mathrm{mol} . \mathrm{m}^{-2} \cdot \mathrm{s}^{-1}$, fornecida por lâmpadas fluorescentes, e umidade relativa do ar próxima a $52 \%$; e fitotron com intensidade luminosa de $450 \mu \mathrm{mol} . \mathrm{m}^{-2} . \mathrm{s}^{1}$, fotoperíodo de 16 horas luz, temperatura de $28^{\circ} \mathrm{C} \pm 1 \mathrm{e}$ umidade relativa do ar de, aproximadamente, $72 \%$. $\mathrm{O}$ autor concluiu que o fitotron foi o melhor ambiente para crescimento dos porta-enxertos de macieira, o que se deve ao fato de a intensidade luminosa ser de $450 \mu \mathrm{mol} . \mathrm{m}^{2} . \mathrm{s}^{-1} \mathrm{e}$ a temperatura ser mais elevada, o que ativa, com maior intensidade, o metabolismo das plantas, especialmente a fotossíntese.

De modo geral, as mudas de pessegueiro, após a enxertia, são conduzidas em telado coberto com sombrite, ou mesmo em viveiro em campo aberto, portanto, sem nenhum controle do ambiente ao qual estão expostas.

A antecipação da produção de mudas possibilita maior produtividade do viveiro, maior rotatividade no uso da infraestrutura montada e aumento da eficiência de utilização da mão-de-obra especializada (Souza et al. 1997).

Neste trabalho, avaliou-se a influência de diferentes ambientes de condução das mudas e três tipos de enxertia, na taxa de pegamento do enxerto e no tempo de obtenção de mudas de pessegueiro.

\section{MATERIAL E MÉTODOS}

O trabalho foi conduzido no Setor de Fruticultura da Universidade Federal de Lavras (MG), no período de novembro de 2003 a novembro de 2004.

Os tratamentos consistiram em três ambientes de condução das plantas (campo aberto, telado/ sombrite e estufa plástica) e três tipos de enxertia (borbulhia em T, borbulhia em placa e garfagem).

O telado, coberto com sombrite $50 \%$, apresentava $15 \mathrm{~m}$ de comprimento, $6 \mathrm{~m}$ de largura e 3,5 m de altura. A estufa plástica apresentava $18 \mathrm{~m}$ de comprimento, 6,5 m de largura e 3,5 $\mathrm{m}$ de altura, nas bordas, e, aproximadamente, $4,5 \mathrm{~m}$ de altura, no centro. A estufa possuía sistema para controle automático de 
umidade (80-85\% UR), com ventilação realizada por meio de ventiladores.

Durante o período de condução do experimento, as médias mensais de temperatura mínima e máxima, dentro do ambiente telado, da estufa plástica e em campo aberto, foram monitoradas por meio de termômetros de mínima e máxima (Figura 1).

$\mathrm{O}$ delineamento experimental adotado foi o inteiramente ao acaso, em esquema fatorial $3 \times 3$ (três ambientes e três tipos de enxertia), com quatro repetições e 12 plantas por parcela.

Para a obtenção dos porta-enxertos, foram utilizados caroços de frutos sadios da cultivar 'Okinawa', oriundos de plantas matrizes do Instituto Agronômico de Campinas (IAC). Os caroços foram obtidos a partir de frutos maduros e por meio de lavagens sucessivas em água corrente, para a eliminação do excesso de polpa. Os caroços foram colocados em caixas plásticas $(40 \mathrm{~cm}$ de comprimento x $30 \mathrm{~cm}$ de largura x $15 \mathrm{~cm}$ de altura), contendo serragem fina, e foram, então, acondicionados em refrigerador, por 60 dias, para a quebra da dormência fisiológica, sendo umedecidos 2 a 3 vezes por semana.

Após o período de estratificação, os caroços foram quebrados, com o auxílio de um torno mecânico, para a extração das amêndoas. As amêndoas foram semeadas em bandejas de isopor, com 72 células, contendo substrato constituído de terra de barranco (podzólico vermelho-amarelo) + areia, na proporção $3: 1 \mathrm{v} / \mathrm{v}=600 \mathrm{~g}$ de Super Fosfato Simples $/ \mathrm{m}^{3}$. Quando as plântulas atingiram, aproximadamente, $15,0 \mathrm{~cm}$ de altura, elas foram repicadas para sacolas plásticas

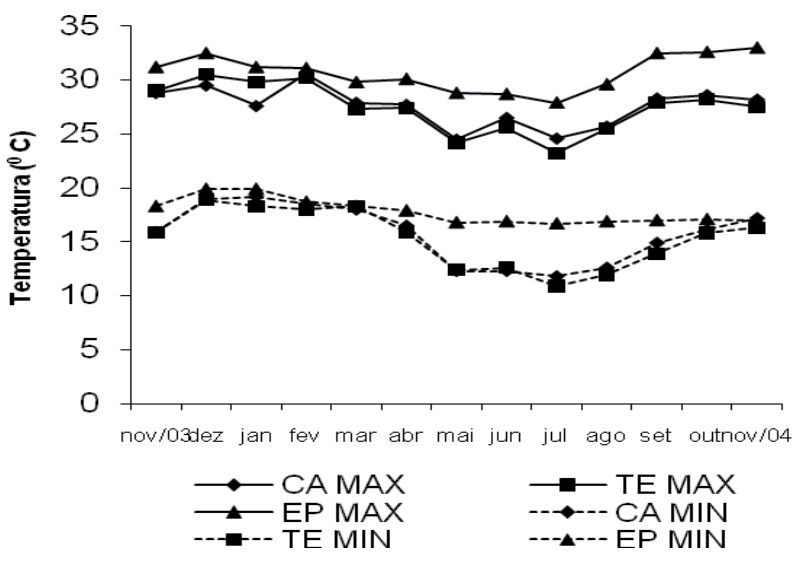

Figura 1. Temperaturas mínimas e máximas, registradas em campo aberto (CA), telado (TE) e estufa plástica (EP), no período de novembro de 2003 a novembro de 2004 (Lavras, MG, 2008).
$(21 \mathrm{~cm} \times 27 \mathrm{~cm})$, contendo o mesmo substrato das bandejas.

Antes da enxertia, os porta-enxertos de pessegueiro 'Okinawa' que apresentavam padrão desejado ( $\pm 70 \mathrm{~cm}$ de altura e 6-8 $\mathrm{mm}$ de diâmetro) passaram por uma toalete, onde foram retiradas as brotações até a altura de, aproximadamente, $40 \mathrm{~cm}$, para facilitar a realização da enxertia.

As enxertias foram realizadas a $15 \mathrm{~cm}$ de altura, a partir do colo do porta-enxerto. Dependendo do tipo de enxertia, foram utilizadas gemas ou garfos com duas gemas da cultivar de pessegueiro 'Diamante'. As enxertias foram realizadas assim que os porta-enxertos atingiram o ponto ideal para sua realização, de acordo com o ambiente em que se encontravam (novembro de 2003, nos porta-enxertos conduzidos em estufa plástica, e janeiro de 2004, para os conduzidos em telado e condição de campo). As enxertias foram realizadas por apenas um enxertador, com grande experiência na realização das mesmas.

Doze dias após a enxertia, foi realizado o arqueamento das copas dos porta-enxertos, onde foi feito o tombamento da parte aérea, para forçar a brotação da gema enxertada, e, 30 dias após, foi realizado o corte definitivo das copas. Foram realizados os tratos culturais necessários ao bom desenvolvimento das mudas, seguindo recomendações descritas por Alvarenga et al. (1997). As mudas foram mantidas nas diferentes condições ambientais, de acordo com os tratamentos pré-estabelecidos, até atingirem a primeira poda de formação.

Foram avaliados a porcentagem de pegamento do enxerto, 20 dias após a realização da enxertia, e o tempo para a muda atingir $50 \mathrm{~cm}$ de altura, a partir da enxertia (primeira poda de formação).

Os dados obtidos foram submetidos a análise de variância (teste $\mathrm{F}$ ) e as médias dos tratamentos comparadas pelo teste Tukey, a 5\% de significância, utilizando-se o programa Sisvar-UFLa (Ferreira 2000).

\section{RESULTADOS E DISCUSSÃO}

Com relação ao tempo para que as mudas atingissem o ponto ideal para a realização das enxertias, verificou-se que a estufa plástica foi o melhor ambiente, ou seja, fez com que as plantas atingissem o ponto ideal para a enxertia com maior rapidez $(179,37$ dias) que nos ambientes em campo aberto (254 dias) e telado (268 dias). 
O pegamento da enxertia não sofreu influência dos tratamentos. A porcentagem média de pegamento dos três tipos de enxertias foi de $91,94 \%$ (Tabela 1), independentemente do ambiente ao qual ficaram expostos, ou seja, a estufa plástica, o telado e campo aberto não interferiram no pegamento das enxertias, sendo, também, indiferente o tipo de enxertia. Este resultado corrobora o obtido por Chalfun \& Hoffmann (1997), que destacam que, em condições ambientais adequadas de temperatura, umidade e luminosidade, obtêm-se, facilmente, pegamentos superiores a $90 \%$, na enxertia de pessegueiro. Portanto, os três ambientes estudados apresentaram condições ambientais adequadas para a realização das enxertias.

Em trabalho realizado para verificar o índice de pegamento de quatro clones de ameixeira, sobre o porta-enxerto de pessegueiro 'Okinawa', Visioli et al. (2002) verificaram elevado índice de pegamento $(100 \%)$ na enxertia de "janela aberta", em todos os clones estudados.

Com relação ao tempo médio para que as mudas atingissem a primeira poda de formação, pode-se observar (Tabela 2) que, em todos os ambientes estudados, as mudas resultantes da enxertia de garfagem de fenda cheia atingiram a altura adequada em tempo inferior aos demais tratamentos.

Tabela 1. Taxa de pegamento de enxertos (\%) da cv. 'Diamante', em porta-enxerto de pessegueiro 'Okinawa', em diferentes ambientes e tipos de enxertias (Lavras, MG, 2008).

\begin{tabular}{lccc}
\hline \multirow{2}{*}{ Tipos de enxertia } & \multicolumn{3}{c}{ Taxa de pegamento dos enxertos (\%) } \\
\cline { 2 - 4 } & Estufa plástica & Campo aberto & Telado \\
\hline Borbulhia em T & $90,00 \mathrm{a} *$ & $92,50 \mathrm{a}$ & $91,25 \mathrm{a}$ \\
Borbulhia em placa & $93,75 \mathrm{a}$ & $93,75 \mathrm{a}$ & $91,25 \mathrm{a}$ \\
Garfagem & $90,00 \mathrm{a}$ & $91,25 \mathrm{a}$ & $91,25 \mathrm{a}$ \\
\hline * Médias seguidas da mesma letra, na coluna, não diferem, significativamente, entre \\
si, pelo teste Tukey, a 5\% de probabilidade. C.V. (\%): 4,25; DMS: 3,957.
\end{tabular}

Tabela 2. Tempo médio (dias) para as mudas de pessegueiro Prunus persica Batsch (L.) cv. 'Diamante' atingirem a primeira poda de formação, com diferentes tipos de enxertias e ambientes (Lavras, MG, 2008).

\begin{tabular}{lccc}
\hline \multirow{2}{*}{ Enxertia } & \multicolumn{3}{c}{ Tempo médio (dias) } \\
\cline { 2 - 4 } & Campo aberto & Telado & Estufa plástica \\
\hline Borbulhia T & $270,25 \mathrm{Ac} *$ & $275,50 \mathrm{Bc}$ & $341,25 \mathrm{Cb}$ \\
Borbulhia placa & $266,75 \mathrm{Ab}$ & $269,25 \mathrm{Ab}$ & $339,50 \mathrm{Bb}$ \\
Garfagem & $223,00 \mathrm{Ba}$ & $239,00 \mathrm{Ca}$ & $142,50 \mathrm{Aa}$ \\
\hline * Médias seguidas da mesma letra minúscula, na coluna, e maíscula, na linha, não \\
diferem, significativamente, entre si, pelo teste Tukey, a 5\% de probabilidade. \\
C.V. (\%): 0,55; DMS: $2,525$.
\end{tabular}

Os porta-enxertos conduzidos em estufa plástica ficaram aptos à enxertia em novembro de 2003, sendo que os enxertos atingiram a primeira poda de formação com 142,50 dias, ou seja, com 4,7 meses. As mudas conduzidas em campo aberto e dentro do telado (Tabela 2) só apresentaram diâmetro ideal para a realização das enxertias em janeiro de 2004, ficando aptas à comercialização aos 223 dias (campo aberto) e 239 dias (telado) após a sua realização.

O cultivo sob condições de estufa plástica permite que as plantas tenham um desenvolvimento acelerado, com diminuição do tempo do ciclo vegetativo (Sganzerla 1995), podendo diminuir o tempo de obtenção de mudas. Este fato pôde ser observado no presente trabalho, pois as mudas que foram obtidas em menor tempo foram aquelas desenvolvidas em estufa plástica, cujas temperaturas mínimas e máximas, durante o experimento, foram, respectivamente, $17,8^{\circ} \mathrm{C}$ e $30,7^{\circ} \mathrm{C}$ (Figura 1), sempre superiores e menos variáveis que as registradas no telado $\left(15,3^{\circ} \mathrm{C} \mathrm{e}\right.$ $27,4^{\circ} \mathrm{C}$ ) e campo $\left(15,6^{\circ} \mathrm{C}\right.$ e $\left.27,5^{\circ} \mathrm{C}\right)$.

De acordo com Medeiros et al. (2002) e Hoffmann et al. (2003), na produção comercial de mudas de pessegueiro, o principal método de enxertia realizado é a borbulhia de gema ativa, sendo que a garfagem só é adotada no inverno (junho/julho), visando ao aproveitamento de porta-enxertos cuja enxertia de primavera-verão não tenha obtido êxito e naqueles em que os diâmetros não se encontravam adequados, ou ainda para a maximização do uso de material propagativo da cultivar copa, estando as mudas aptas à comercialização, aproximadamente, 12 meses após a enxertia.

Segundo Chalfun et al. (1998), no sistema de taça, a primeira poda de formação deve ser realizada na altura de 50-60 cm, logo acima de uma gema. Conforme os resultados obtidos no presente trabalho, observou-se que a enxertia de garfagem propiciou o menor número de dias, desde a sua realização até a primeira poda de formação, em todos os ambientes estudados. Estes resultados são diferentes dos citados por Chalfun \& Hoffmann (1997) e Hoffmann et al. (2003), quanto ao tempo de produção da muda de pessegueiro, quando se realiza a enxertia de garfagem, provavelmente devido à época da sua realização. Segundo estes autores, a enxertia de garfagem de fenda cheia é, tradicionalmente, realizada no inverno e, no presente trabalho, ela foi realizada em novembro, nas plantas que estavam sendo conduzidas na estufa plástica, e em janeiro, nas plantas do telado e campo 
aberto, portanto, no período de primavera-verão, com registros de temperaturas mais elevadas.

Com relação aos outros tipos de enxertias que foram feitas nas mudas produzidas em estufa plástica, verificou-se que as enxertias de borbulhia em $\mathrm{T}$ ou em placa, realizadas também no mês de novembro de 2003, tiveram perfeita soldadura das borbulhias, porém, só começaram a brotar no mês de setembro de 2004. Este resultado mostra que as borbulhias, apesar de terem sido coletadas no mês de novembro de 2003, tiveram comportamento de gemas dormentes e não de gemas ativas, como era o esperado, pois as mesmas só brotaram na primavera do ano seguinte. No entanto, se as gemas utilizadas nesta enxertia não estivessem dormentes, e sim aptas para a brotação imediata, as mudas atingiriam a primeira poda de formação mais rapidamente.

De acordo com Hoffmann et al. (2003), na borbulhia de gema dormente, ocorre a soldadura do enxerto, mas não há brotação, a qual somente ocorrerá após a saída da dormência, durante o ciclo seguinte. O pegamento, normalmente, é elevado, mas a gema pode morrer durante o inverno, especialmente se, devido à ocorrência de temperaturas elevadas durante o outono, ocorrer a brotação antecipada da cultivar copa. Todavia, apesar do maior período constatado para a produção deste tipo de muda, observa-se que ele ainda foi menor (aproximadamente 11,4 meses) do que o citado por Hoffmann et al. (2003), de 15 meses, nas condições do sul do Brasil e na maioria das regiões produtoras de mudas.

Já as mudas produzidas em campo aberto e dentro do telado, cujas enxertias de borbulhia em $\mathrm{T}$ e placa foram realizadas no mês de janeiro de 2004, portanto com gemas ativas que brotaram mais rapidamente, em relação à estufa plástica, tiveram um menor período entre a realização das enxertias e a primeira poda de formação (aproximadamente 9 meses), ficando dentro do período normal (9 meses) da produção comercial de mudas de pessegueiro, utilizando borbulhia de gema ativa (Chalfun \& Hoffmann 1997). Segundo Pasqual et al. (2001), como na primavera-verão as células estão em plena atividade metabólica e mitótica, os tecidos cicatrizam com mais facilidade e há bom e rápido pegamento.

De acordo com Fachinello et al. (2005), para a realização da enxertia em placa, o porta-enxerto deve apresentar um diâmetro de 15-25 mm, sendo, portanto, maior do que o necessário para a enxertia em T. Porém, neste estudo, a enxertia de placa foi realizada em plantas com o mesmo diâmetro necessário para a borbulhia em T (6-8 mm). Verifica-se, na Tabela 2, que as mudas oriundas da enxertia de borbulhia em placa atingiram a primeira poda de formação em menor tempo que aquelas de borbulhia em $\mathrm{T}$, em campo aberto e telado, sendo, portanto, uma boa opção para estes tipos de ambientes de condução de mudas.

\section{CONCLUSÕES}

1. Diferentes ambientes não interferem no pegamento de enxertos da cv. 'Diamante', em porta-enxertos 'Okinawa', nas condições de Lavras.

2. Mudas oriundas de enxertia de garfagem atingem com maior rapidez a primeira poda de formação, independentemente do ambiente de condução.

3. Enxertia de borbulhia em T normal proporciona maior tempo para a realização da primeira poda de formação, em plantas conduzidas em condições de telado e campo aberto.

\section{REFERÊNCIAS}

ALVARENGA, A. A.; SOUZA, C. R. de. Tratos culturais para pessegueiros, ameixeiras, nectarineiras. Informe Agropecuário, Belo Horizonte, v. 18, n. 189, p. 34-43, 1997.

CHALFUN, N. N. J.; HOFFMANN, A. Propagação do pessegueiro e da ameixeira. Informe Agropecuário, Belo Horizonte, v. 18, n. 189, p. 23-29, 1997.

CHALFUN, N. N. J.; PASQUAL, M.; HOFFMANN, A. Fruticultura comercial: frutíferas de clima temperado. Lavras: UFLa/Faepe, 1998.

FACHINELLO, J. C.; HOFFMANN, A.; NACHTIGAL, J. C. Propagação de plantas frutíferas. Brasília. DF: Embrapa, 2005.

FERREIRA, D. F. Manual do sistema Sisvar para análises estatísticas. Lavras: UFLa, 2000.

HOFFMANN, A.; NACHTIGAL, J. C.; BERNARDI, J. Sistema de produção de pêssego de mesa na região da serra gaúcha. 2003. Disponível em: <http://www. embrapa.br>. Acesso em: 21 set. 2003.

MEDEIROS, A. R. M. et al. Cultivo do pessegueiro. 2002. Disponível em: <http://www.embrapa.br>. Acesso em: 28 ago. 2005.

NUNES, J. C. O. Caracterização morfofisiológica de micro-enxertos e mini-enxertos ex-vitro de macieira (Malus sp.). 2001. 106 f. Dissertação (Mestrado em Recursos Genéticos Vegetais)-Universidade Federal de Santa Catarina, Florianópolis, 2001. 
OLIVEIRA, C. R. Cultivo em ambiente protegido. Boletim Técnico CATI, Campinas, n. 232, p. 1-30, abr. 1997.

PASQUAL, M. et al. Fruticultura comercial: propagação de plantas frutíferas. Lavras: UFLa/Faepe, 2001.

PEREIRA, F. M.; MAYER, N. A. Pessegueiro: tecnologias para a produção de mudas. Jaboticabal: Funep, 2005.

PICOLOTTO, L.; BIANCHI, V. J.; FACHINELLO, J. C. Ação de giberelinas e citocininas na germinação de sementes de pessegueiro. Scientia Agraria, Curitiba, v. 8, n. 3, p. 225-232, 2007.

SGANZERLA, E. Nova agricultura: a fascinante arte de cultivar com os plásticos. 5. ed. Guaíba: Agropecuária, 1995.

SIMÃO, S. Tratado de fruticultura. Piracicaba: Fealq, 1998.
SOUZA, P. V. D. et al. Desenvolvimento de citrange "troyer" infectado com fungo micorrízico em dois substratos de cultivo. Pesquisa Agropecuária Brasileira, Brasília, DF, v. 32, n. 10, p. 1039-1045, 1997.

TOFANELLI, M. B. D. et al. Capacidade de enraizamento de estacas lenhosas e semilenhosas de cultivares de pessegueiro. Ciência e Agrotecnologia, Lavras, v. 25, n. 4, p. 840-847, 2001.

VISIOLI, E. L. et al. Estudos da enxertia de clones pré-selecionados de ameixeira utilizando-se como portaenxerto o pessegueiro 'Okinawa'. In: CONGRESSO BRASILEIRO DE FRUTICULTURA, 17., 2002, Belém. Anais... Belém: Embrapa, 2002. 1 CD-ROM. 